\title{
Refletindo sobre a questão da prescrição de medicamentos
}

\author{
Francisco Rosemiro \\ Guimarães Ximenes Neto \\ Diretor de Assuntos Profissionais da ABEn \\ Nacional, Gestão 2004/2007.
}

A Enfermagem Brasileira nos últimos trinta anos tem se desenvolvido com grande intensidade nos Campos da Saúde Coletiva e da Saúde Pública. Na Saúde Coletiva, a Enfermeira vem se apropriando cada vez mais, em seu processo de trabalho, de ferramentas próprias da epidemiologia e do planejamento, além de utilizar-se de teorias e práticas comuns às Ciências Sociais e Humanas. Seu fazer então, vem transcendendo de uma prática estritamente biologicista, flexneriana, com uma concepção de saúde como ausência de doença, a uma prática voltada as necessidades sócio-sanitárias dos sujeitos, de suas famílias e comunidades, numa visão de saúde como qualidade de vida, numa perspectiva do conceito de território, centrado no cuidado holístico, humanizado, equânime, com vistas à cidadania integral.

Ainda neste período, por e como influência da Saúde Coletiva, a Enfermeira participou ativamente no processo de Reforma Sanitária Brasileira e construção do Sistema Único de Saúde - SUS, nos movimentos sociais de participação popular e nos sanitários, e vem colaborando na formulação de políticas públicas de saúde para os diferentes níveis de atenção e setores de regulação e regulamentação do SUS.

$\mathrm{Na}$ Saúde Pública, neste período, a práxis da Enfermeira vem sendo construída, com base nas ações de prevenção de doenças, educação, promoção e proteção da saúde, reabilitação e também no tratamento de doenças. O trabalho da Fundação de Serviços Especiais de Saúde Pública-FSESP e dos Programas de Saúde Pública, Ações Programáticas de Saúde, Programa de Interiorização das Ações de Saúde e Saneamento-PIASS, a partir dos anos 1970 tem enfocado o controle de doenças endêmicas. Ou mesmo, pelas Ações Integradas de Saúde-AIS e o Sistema Único e Descentralizado de Saúde-SUDS no anos 1980, na atenção à saúde materna - no pré-natal, prevenção do câncer ginecológico e de mama-e infantil, ao adolescente e ao jovem, aos portadores de tuberculose, hanseníase, hipertensão arterial sistêmica, Diabetes Mellitus, Infecções Respiratórias Agudas, Doenças Sexualmente Transmissiveis dentre outros.

Com a regulamentação do SUS, no início dos anos 1990 e, conseqüente descentralização de políticas, programas, serviços e ações de saúde, para Estados e Municípios, e com a institucionalização de Programas como o de Agentes Comunitários de Saúde (1991) e o Saúde da Família (1994), o enfermeiro passa a compor uma equipe de saúde, prestando cuidados não mais somente aos sujeitos individualizados, mas também as suas famílias e comunidades, e incrementa/amplia seu processo de trabalho, numa perspectiva comunitária e terapêutica, incluindo-se dentre as diversas práticas, a prescrição medicamentosa e requisição de exames complementares durante a consulta de enfermagem.

No que concerne à prática da prescrição medicamentosa, a Enfermagem dispõe de uma legislação de vanguarda, arrojada, como a Lei do Exercício Profissional - a Lei №. 7.498/1986 - e o Decreto №. 94.406/1987, que asseguram ao enfermeiro como integrante da equipe de saúde, a "prescrição de medicamentos estabelecidos em programas de saúde pública e em rotina aprovada pela instituição de saúde...". Tal prática, devido às necessidades de saúde da população, vem cada vez mais, se constituindo como necessária ao processo de consolidação do SUS e, conseqüente, efetivação da integralidade e da equiidade.

Tanto que, o Ministério da Saúde, após pactuação tripartite - União, Estados e Municípios - e corporativa, vem referendando, através das normatizações em políticas assistenciais e protocolos, não somente a prescrição medicamentosa, como previsto na legislação profissional, em programas de saúde e na Estratégia Saúde da Família, mas também a requisição de exames complementares, conforme estabelecido recentemente na Portaria No $648 / G M / 2006$ do Ministério da Saúde que dispõe sobre a Política Nacional da Atenção Básica.

A Política Nacional da Atenção Básica também assegura ao enfermeiro que atua em municípios onde não há equipes de saúde da família, mas contam com a Estratégia Agentes Comunitários de Saúde, as mesmas premissas. Entretanto a comunidade médica vem incomodando-se/inquietando-se e move-se em busca de sanções jurídicas para estas práticas.

AABEn com o apoio à Enfermagem Brasileira, do Conselho Nacional de Secretários Municipais da Saúde-CONASEMS e do próprio Ministério da Saúde, vem emanando esforços para reverter tal prática 
rudimentar de concorrência corporativa.

A Enfermagem em sua história, sempre teve como referencial de seu cuidar, os sujeitos, suas famílias e comunidades, defendendo as necessidades da população, buscando um sanitarismo resolutivo, efetivo, equânime e de qualidade, que busque a qualidade de vida, a atenção e a cidadania integral, defendendo o direito à saúde da população, e não tomando a saúde como mercadoria, estipêndio. 